\title{
Sobre epidemias, endemias y epizootias: algunos aspectos del desarrollo de la bacteriología en Colombia
}

\author{
Diana Obregón
}

\begin{abstract}
Resumen
En este artículo se estudian algunas epidemias, epizootias y enfermedades ocurridas en lo que hoy es Colombia entre 1849 y 1914. A través de la descripción y el análisis del cólera, del carbón bacteridiano, de la lepra y de la peste, se examinan tanto las organizaciones sociales creadas con el fin de conjurar los peligros que tales acontecimientos acarreaban para la salud pública, como los saberes científicos que se desplegaron y se pusieron en práctica en tales oportunidades. También se examinan algunos de los trabajos de figuras como Juan de Dios Carrasquilla y Federico Lleras Acosta y el papel de algunas instituciones como la Universidad Nacional y los laboratorios de Carrasquilla y de Lleras. Se realiza un análisis de aspectos relevantes del desarrollo de la disciplina científica de la bacteriología en Colombia, sin acudir a los modelos difusionistas según los cuales una disciplina se "recibe" intacta y acabada desde los centros científicos (Europa, en este caso) y colocando el énfasis del análisis tanto en los actores locales, como en los procesos de construcción social de la ciencia. De esta manera, se examinan las necesidades sociales que contribuyeron a organizar laboratorios e instituciones de investigación bacteriológica, así como el tránsito de organizaciones de "notables" hacia el manejo profesional de las emergencias sanitarias por parte de médicos y especialistas.

\section{Epidemics, endemics and epizootics: some aspects of bacteriology's development in Colombia}

This article studies some epidemics, epizootics and diseases which occurred betwen 1849 and 1914 in what is today Colombia. The social organisations created for public health in order to face the spread of cholera, anthrax, leprosy and the plague, are also examined. The scientific knowledge which was put into practice in those cases, through the scientific work of Juan de Dios Carrasquilla and Federico LLeras Acosta, is also analysed. The role of institutions, such as the Universidad Nacional and Carrasquilla's and Lleras's laboratories is considered. According to diffusionist models, a scientific discipline is "received" intact from scientific centres (Europe, in this case) and places analysis emphasis on local actors as well as on science's social construction processes. Thus, the social needs which contributed to the founding of laboratories and institutions for bacteriological research are examined. The transition from lay organisations to the medical and professional management of sanitary emergencies is also analysed.
\end{abstract}

Departamento de Historia, Universidad Nacional de Colombia, Santa Fe de Bogotá, Colombia.

Recibido para su publicación: el 27 de febrero de 1998. - Aprobado para su publicación: 8 de mayo de 1998. 
La "revolución" científico-médica que significó la teoría microbiológica de finales del siglo XIX fue ampliamente conocida en Colombia ${ }^{1}$. Las ideas y los métodos de Pasteur y de Koch (en traducciones francesas o inglesas) se difundieron pronto entre los médicos colombianos quienes se referían con frecuencia a la importancia del "descubrimiento" de "lo infinitamente pequeño". Esta rápida propagación se puede explicar de manera general por la influencia que desde la temprana república ejercieron la ciencia y la cultura francesas. Durante el siglo XIX, médicos coIombianos viajaban a París o a Lyon a continuar sus estudios, manteniendo un contacto epistolar con sus pares en Colombia y con frecuencia traduciendo artículos y discusiones de la Academia de Medicina de París. Sin embargo, de manera más precisa, es necesario explorar el papel activo que cumplió la comunidad médica colombiana, tema que examino en este artículo. En efecto, la profesión médica se ocupó de expandir y de poner en práctica la bacteriología, uno de los saberes científicos considerados como más novedosos, como una manera de acrecentar y de consolidar su "capital cultural" "

Como han señalado ya varios autores, es preciso trazar una historia de la ciencia para América Latina que sea más simétrica con respecto a Europa 0 , quizás, menos asimétrica ${ }^{3}$ Colocar el énfasis en lo local ha sido la recomendación de estos mismos autores ${ }^{4}$. En este trabajo me propongo mostrar que las disciplinas científicas, las teorías o los paradigmas no viajan solos ni se convierten en conocimiento científico universal por la sola fuerza de su certeza como ciencia, que es uno de los supuestos que se en-

\footnotetext{
"El carácter estrictamente "revolucionario" de la obra de Pasteur ha sido cuestionado por algunos autores. Según Anne-Marie Moulin, tanto Pasteur como los pasteurianos exageraron los aspectos innovativos de su teoría, al denominarla una "revolución" y considerarla "el" punto de partida de la medicina moderna. Ver: Moulin AM. Bacteriological research and medical practice in and out of the Pastorian School. In: Feingold M, LaBerge A, editors. French medical culture in the 19th century. Amsterdam: Rodopi; 1994. p.327-49.

${ }^{2}$ Este concepto es del sociólogo francés Pierre Bourdieu. Ver: The specificity of the scientific field and the social conditions of the progress of reason. In: Social science information 1975;14(6):19-47.
}

cuentran implícitos en la teoría difusionista. Se necesitan agentes activos, actores históricos e instituciones que conviertan a las teorías en verdaderas. Para comprender estos procesos de construcción social del conocimiento científico, en este artículo comparo algunos momentos de la historia de Colombia del siglo XIX y de comienzos del siglo $X X$ en los cuales estuvo comprometida la salud pública para examinar cómo los grupos sociales interesados respondieron a estas situaciones.

\section{La epidemia de cólera de 1849}

A mediados de 1849, el cólera llegó a Cartagena, en las costas de la Nueva Granada. Se trataba de la misma epidemia que habia invadido París en 1832, causando un enorme pánico entre la población ${ }^{5}$.Los miembros de la Sociedad filantrópica se reunieron el 5 de agosto de 1849 en la sala municipal de la ciudad de Bogotá, junto con un número considerable de personas "respetables", con el fin de formar una Junta de Sanidad. El gobernador de la provincia de Bogotá expidió un decreto atribuyendo a la Sociedad filantrópica las funciones y deberes de Junta de Sanidad provincial ${ }^{6}$. La principal

${ }^{3}$ El tema de la asimetría fue puesto de presente hace más de dos décadas por el sociólogo David Bloor como una crítica a las versiones según las cuales la ciencia por ser conocimiento verdadero no requeriría explicaciones sociológicas. El llamado de Bloor a la simetría consiste en indicar que tanto las falsas creencias como las verdaderas encuentran su fundamento en la sociedad. Véase: Bloor D. Knowledge and social imagery. 2nd ed. Chicago: The University of Chicago Press; 1976/1991.

${ }^{4}$ Lafuente A, Sala J. Ciencia colonial y roles profesionales en la América española. In: Quipu Revista Latinoamericana de Historia de las Ciencias y la Tecnología 1989;6 (3):387-403; Saldaña J, editor. Los orígenes de la ciencia nacional. México: Sociedad Latinoamericana de Historia de las Ciencias y la Tecnología; 1992; Chambers DW. Locality and science: myths of centre and periphery. In: Lafuente A, Helena A, Ortega ML, editores. Mundialización de la ciencia y cultura nacional. Actas del Congreso internacional de ciencia, descubrimiento y mundo colonial. Madrid: Doce Calles; 1993. p.605-17; Cueto M, editor. Missionaries of science: the Rockefeller Foundation and Latin America. Bloomington: Indiana University Press; 1994, y Restrepo O. Cómo huir de la recepción y salir de la periferia. Ponencia presentada en el coloquio "Culturas científicas y saberes locales: asimilación, hibridación, resistencia?" Universidad Nacional de Colombia, noviembre 5-7, 1997. 
misión de esta junta sería la de "obrar para evitar la terrible enfermedad del cólera morbo" y estudiar el mejor modo de atender a la salvación de los habitantes en caso que la ciudad fuese atacada por la epidemia. El científico Manuei Ancízar, quien posteriormente sería miembro de la Comisión Corográfica y primer rector en propiedad de la Universidad Nacional de los Estados Unidos de Colombia, fue comisionado junto con otros para recaudar una contribución voluntaria que sirviera para socorrer a los enfermos pobres. El pedagogo y escritor Lorenzo María Lleras y los médicos Félix Merizalde y Antonio Vargas Vega fueron encargados de promover el establecimiento de hospitales. Se acordó también que la Sociedad filantrópica se reuniera todos los domingos en el Salón de Grados de la Universidad, además de las veces que fuera convocada por el ciudadano presidente de la República, José Hilario López, quien era, al mismo tiempo, presidente de la misma.

Unos días más tarde, el ciudadano presidente López encargó del aseo y salubridad de la capital a una comisión compuesta, entre otros, por escritores, intelectuales y políticos. Entre ellos se encontraban: José María Vergara, Medardo Rivas, Manuel Ancízar, José María Samper y Salvador Camacho Roldán. Ninguno de ellos era médico. De manera inmediata, el presidente de esta comisión dirigió una circular a los provinciales de las comunidades religiosas (Agustinos descalzos y Franciscanos) y al convento de predicadores con el fin de establecer si estas comunidades podrían albergar enfermos en caso de invasión del cólera y en caso de que ya no pudiera asistirse a los enfermos en los hospitales generales que se establecerían. Estos hospitales que se improvisaban en tiempo

\footnotetext{
${ }_{5}^{5}$ Sobre la epidemia de cólera del siglo XIX existe abundante literatura, aunque no sobre el caso de Colombia. Véase, por ejemplo, Rosenberg CE. The Cholera Years: The United States in 1832, 1849 y 1866. Chicago: University of Chicago Press, 1962; Delaporte F. Disease and Civilization: The Cholera in Paris, 1832. Cambridge, MA: MIT Press, 1986; Arnold D. Cholera and Colonialism in India. In: Past \& Present 1986; 113: 118-151 y Olivier LV. El cólera y los barrios de Guadalajara en 1833 y en 1850. In: Cueto $M$, editor. Salud, cultura y sociedad en América Latina. Lima: IEP, 1996: 87-109.

${ }^{6}$ El filántropo, Bogotá, 17 de Agosto de 1849, No. 1.
}

de epidemia no eran más que lugares de aislamiento para los contagiados sin que realmente se les ofreciera auxilio médico. ${ }^{7}$

El médico Bernardo Espinosa, informaba a través del periódico El filántropo, que el "cólera morbo asiático" se entendía como un envenenamiento miasmático no contagioso pero que, sin embargo, se adquiría en una atmósfera impregnada de esos principios morbíficos, reproducidos por los enfermos y los cadáveres de los que le habían padecido. ${ }^{8}$ La noción de miasma en su origen griego estaba relacionada con la idea de polución, contaminación tanto física como moral. Los miasmas, como contaminantes del aire, se convirtieron en una explicación natural de las epidemias, por contraposición a la idea del castigo divino. Hasta bien entrado el siglo $\mathrm{XIX}$, los miasmas entendidos como emanaciones de sustancias en putrefacción se consideraban causa de las enfermedades cuyo origen se sospechaba era externo al organismo. De ahí que los primeros higienistas y reformadores sociales dedicasen todos sus esfuerzos a la limpieza del aire. ${ }^{9}$ Espinosa se encontraba dentro de esta línea de pensamiento.

Según este médico, como primera medida preventiva se debería interrumpir la comunicación con los puntos infestados por el cólera. Había que impedir que salieran de Cartagena los individuos que llevaban consigo los gérmenes de la enfermedad, a través de cordones sanitarios y de cuarentenas instaladas cerca de esos pun-

\begin{abstract}
${ }^{7}$ La historia de los hospitales se ha investigado poco en Colombia. Para una versión somera, véase, Soriano A. Crónica del Hospital de San Juan de Dios desde su fundación hasta su administración por la Junta de Beneficencia de Cundinamarca. 1564-1869. Bogotá: Junta de Beneficencia de Cundinamarca, 1964. Para el caso de España, véase, por ejemplo, García D. El Hospital Real de Santiago (1499-1804). La Coruña: Fundación Pedro Barrie de la Maza, 1983: 25-34 y para la historia de los hospitales en Inglaterra, Italia y los Estados Unidos, véase: Granshaw L. and Porter R, editors. The Hospital in History. London: Routledge, 1989.
\end{abstract}

${ }^{8}$ Opúsculo sobre el cólera por B. Espinosa, El filántropo, Bogotá, 17 de Agosto de 1849, No. 1.

${ }^{9}$ Hannaway C. Environment and Miasmata. In: Bynum WF. y Porter R. editors. Companion Encyclopedia of the History of Medicine vol. 1 London: Routledge, 1993: 292308. 
tos. Si de todas maneras el cólera seguía en dirección a Bogotá, habría que adoptar "un buen régimen de policía". En este caso, todos los cuidados debían dirigirse a mejorar las condiciones del aire. Para ello era preciso el aseo general, hacerlo renovar con frecuencia y dispersar materias propias para purificarlo de sustancias deletéreas. Para beber, debía utilizarse el agua que corría libremente. También se recomendaba la templanza, un régimen moral, la fijación de horas para dormir y el aseo personal: un baño general tibio, por lo menos, cada ocho días se consideraba excelente preservativo, además de "arreglar la imaginación para que desaparecieran los temores". Según los conocimientos de la época, "habiendo tranquilidad de conciencia, aseo, sobriedad, templanza y método no da el cólera". Espinosa indicaba que, en Cartagena, las gentes que el cólera había atacado con más predilección eran las que vivían en el desaseo y tenían hábitos de embriaguez. Según este médi$\mathrm{co}$, no se conocía la causa general que producía el cólera morbo epidémico, pero había muchas causas que ayudaban a su desarrollo: la infracción de las reglas higiénicas, un aire frío y húmedo, los calores fuertes, las mutaciones repentinas de la atmósfera, todas las sustancias irritantes, las pasiones intensas, especialmente el terror y la tristeza, y los placeres del amor.

Es importante examinar los rasgos de la acción social que se desarrolló en la Nueva Granada a propósito de esta emergencia. Grupos de notables -políticos, escritores, intelectuales (no de profesionales)- se encargaron del manejo de la epidemia. No existían organismos específicos para atender estas situaciones, que hoy definimos como de salud pública, ni existía un cuerpo médico organizado. Se crearon comités de emergencia con participación de los médicos, pero éstos no jugaban un papel determinante en ellos. ${ }^{10} \mathrm{Se}$ acudió a las órdenes religiosas puesto que ellas eran quizás las únicas instituciones

\footnotetext{
${ }^{10}$ Según G. Rosen, la epidemia de cólera del siglo XIX estimuló la creación de comités permanentes de salud pública tanto en Inglaterra como en Estados Unidos. Véase: A History of Public Health Expanded ed. Baltimore: The Johns Hopkins University Press, 1993: 253-54. Por el contrario, en la Nueva Granada el cólera no jugó un papel tan importante.
}

con alguna capacidad para asistir a la comunidad bogotana, pero también porque se entendía la salubridad pública como un asunto relacionado con la caridad cristiana. ${ }^{11}$ Así mismo, las reglas higiénicas que los médicos proponían para evitar el contagio eran, en su mayoría, preceptos de orden moral. Las causas se suponían múltiples, por tanto los remedios se creían múltiples también. Al saber de la época todavía la idea de una causa única como agente productor del cólera le era ajena.

\section{Una epizootia: la fiebre carbonosa de 1869}

Una segunda epidemia, cuyo manejo contrasta con el anterior, tuvo lugar en la sabana de Bogotá, veinte años más tarde. Se trataba en este caso de una epizootia, esto es, una epidemia del ganado que también amenazaba la vida de la población. El 18 de enero de 1869 se presentó por primera vez en un hato en el distrito de Fontibón, una enfermedad desconocida para los hacendados y que mató en un día siete vacas. Desde ese día se presentaron muchos otros casos en el mismo distrito y, además, en Funza y en Usme. Manuel Ancízar, entonces rector de la recientemente fundada Universidad Nacional de los Estados Unidos de Colombia, alarmado por la epizootia de la sabana de Bogotá y con el fin de prevenir una epidemia en la población, decidió promover una investigación científica acerca de las causas, los caracteres y las consecuencias de aquella enfermedad. De esta manera, el rector Ancízar comisionó a los doctores Andrés María Pardo y Antonio Ospina, profesores de la Escuela de Medicina de la Universidad, para realizar tal investigación. En marzo de 1869, los doctores Pardo y Ospina presentaron una memoria, que fue ratificada por el Consejo de la Escuela de Medicina y publicada en el Diario Oficial. En ella proponían las medidas necesarias para impedir el desarrollo de la epizootia. ${ }^{12}$

Después de haber realizado el examen y la autopsia, los médicos diagnosticaron una fiebre carbonosa cuyo virus, afirmaban, era "transmiti-

\footnotetext{
${ }_{11}$ Sobre las prácticas curativas desplegadas por la Iglesia en la Europa medieval, véase: Sheils WJ. editor. The Church and Healing. Oxford: Basil Blackwell, 1982.
} 
do al hombre por una especie de inoculación que desarrolla la pústula maligna". ${ }^{13}$ Afirmaban que la fiebre carbonosa era siempre producida por miasmas pútridos y por la permanencia de los animales en lugares pantanosos y cenagosos. Citaban a veterinarios franceses, entre ellos a Joseph Davaine, quien sostenía que en la sangre de los animales atacados por enfermedades carbonosas se presentaban unos corpúsculos particulares que los micrógrafos llamaban bacteridios. ${ }^{14}$ En el lenguaje científico de la época, las palabras virus y germen tenían un sentido semejante y se referían a cualquier microorganismo tóxico o venenoso. Los llamados micrógrafos correspondían a lo que después se llamarían bacteriólogos y los bacteridios a microorganismos en general.

La referencia al patólogo francés Casimir Joseph Davaine en la memoria resulta sugestiva. Davaine trabajaba desde 1835 en el servicio del profesor Rayer, en el Hospital de la Caridad en París. En 1850 fue llamado por una asociación de veterinarios para estudiar una enfermedad mortal, muy común entre las ovejas, llamada carbón. A través de una serie de experiencias, este médico mostró que la enfermedad se podía transmitir por inoculación de la sangre de un animal enfermo a uno sano. Al observar la sangre al microscopio detectó pequeños cuerpos inmóviles en forma de filamentos, cuerpos que estaban ausentes en la sangre de los animales sanos y que no podían ser resultado de la descomposición de la sangre después de su muerte puesto que se encontraban allí presentes desde antes. Hasta aquí llegó la investigación de Davaine. Aproximadamente diez años después, en 1861, Louis Pasteur publicó un trabajo en el cual señalaba que "pequeños cuerpos en forma de filamentos" eran los responsables de la fermentación butírica. Al leer esta comunica-

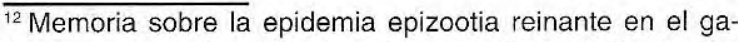
nado vacuno y lanar de la sabana de Bogotá. In: Anales de la Universidad Nacional de los Estados Unidos de Colombia: Repertorio de instrucción pública, literatura, filosofía, y ciencias matemáticas, físicas, médicas y legales, 1869, 2: 28-38.

${ }^{13}$ Ibid.: 33.

14 Ibid.: 35
}

ción, Davaine concluyó que esos pequeños cuerpos que él había observado podrían jugar un papel semejante al de los fermentos de Pasteur y lanzó la hipótesis de la intervención de microorganismos en el desarrollo de algunas enfermedades. De esta manera, los historiadores consideran que el microorganismo del carbón fue uno de los primeros en ser identificado. Sin embargo, para la historiografía tradicional, el "descubrimiento" de Davaine cobrará sentido sólo a partir de la obra de Pasteur. ${ }^{15}$ Desde luego, para los doctores Pardo y Ospina, Davaine era sólo un autor más que trataba el tema del carbón. La discusión del papel de los gérmenes en la producción de enfermedades parecía serles desconocida.

Una vez establecido el diagnóstico, Pardo y Ospina exponen en su memoria el método curativo y las reglas higiénicas que se deben tener en cuenta para prevenir la enfermedad del carbón: "en cuanto sea posible es necesario separar los animales de los pantanos y de todo género de aguas detenidas y proporcionarles lugares sombríos a fin de evitar los efectos del fuerte calor, que es una de las causas de la enfermedad carbunculosa". ${ }^{16}$

Por esta misma época, el 10. de febrero de 1869 , el tema de la fiebre carbonosa se discutió en una sesión de la Academia de Ciencias de París presidida por Claude Bernard. En aquella sesión, Davaine disputó con una comisión del Ministerio de Agricultura francés que confundía los filamentos del carbón propiamente dicho con los de la putrefacción. Una traducción al castellano del resumen de estas discusiones fue publicada en el periódico de la Universidad Nacional. ${ }^{17}$

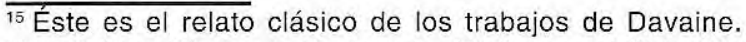
Ver: Geison GL. Louis Pasteur. In: Dictionary of Scientific Biography. New York: Scribner and Sons, 1974: 351-416. Para una excelente versión divulgativa, véase: Raichvarg D. Louis Pasteur l'empire des microbes. Paris: Gallimard, 1995: 33-36. No me detendré aquí en la crítica de las nociones de "descubrimiento", "observación" e hipótesis.

${ }^{16}$ Memoria sobre la epidemia epizootia: 36 .

${ }^{17}$ Academia de Ciencias. Sesión del 1o. de febrero de 1869.-Presidencia del doctor Claudio Bernard. Anales de la Universidad 1869; 2: (41-43).
} 
Resulta interesante el contraste entre el manejo de la epizootia de la sabana comparado con el de la epidemia de cólera. Entre 1849 y 1869 las teorías sobre las enfermedades no se modificaron radicalmente en lo que hoy es Colombia: las nociones de los "miasmas" y del clima como productores de epidemias y de enfermedades aún se mantenían como referencias conceptuales. En cambio, ocurrieron cambios institucionales significativos: no solamente la Nueva Granada se había convertido en los Estados Unidos de Colombia, sino que en 1869 ya existía, desde hacía por lo menos dos años, una escuela de formación de médicos en la Universidad Nacional. Después del desastre que significó para los estudios universitarios la ley de 1850 que declaraba innecesario el título profesional para ejercer la medicina, la nueva escuela parecía destinada a tener una vida estable. En el momento de la epizootia, los médicos de Bogotá ostentaban un saber profesional, práctico, que puesto al servicio de los negocios prometía ser útil para ganaderos y hacendados. De manera semejante, uno de los rasgos más destacados de la ciencia de Pasteur sería su carácter práctico; a tal punto que muchos afirman que con Pasteur nació el concepto de "ciencia aplicada". Pardo y Ospina no eran pastorianos (como se les decía a los seguidores de Pasteur) pero estaban muy cerca de serlo puesto que el tipo de cuestiones que debían resolver eran semejantes. Por lo demás, los médicos de la Universidad Nacional se encontraban al tanto de los debates de la Academia de Medicina de París, donde estas cuestiones estaban a la orden del día. Desde el análisis epistemológico, podría objetarse que la definición conceptual en los dos casos (Pardo y Ospina, de un lado y Pasteur, del otro) era radicalmente distinta. Sin embargo, el análisis sociológico muestra que la ciencia de Pasteur y de Koch se forjó de una manera semejante: resolviendo problemas prácticos de la industria francesa, en un caso, y de la salud pública alemana, en el otro. ${ }^{18}$

Posteriormente los médicos y profesores de la Universidad Nacional ya habían adquirido la fuerza social suficiente para agruparse como cuerpo profesional. En efecto, en 1873 fundaron la So- ciedad de Medicina y Ciencias Naturales de Bogotá que en 1891 se convirtió en Academia Nacional de Medicina. Un proceso semejante se vivió en Medellín en 1887, al crearse la Academia de Medicina de Medellín. También en Popayán, Cartagena y Bucaramanga se erigieron sociedades médicas. El propósito de estas asociaciones profesionales consistente en crear una medicina nacional formaba parte de la cultura de la época, según la cual la ciencia debía estar al servicio de la construcción de la nación. ${ }^{20} \mathrm{La}$ salubridad pública y la difusión de los principios de la higiene se convirtieron en importantes tareas de las sociedades médicas. Un pueblo sano, sería un pueblo fuerte para el trabajo y para el progreso nacional. En este momento ya se percibía una diferencia nítida en Colombia entre "grupos de notables" convocados en una situación de emergencia y un cuerpo profesional dotado de un saber positivo que indicaba al Estado cuáles eran sus obligaciones en materia de salud pública. La ciencia francesa continuaba siendo un punto de referencia obligado.

\section{Una enfermedad endémica: el caso de la lepra}

En junio de 1884, el médico Gabriel J. Castañeda informó a la Sociedad de Medicina y Ciencias Naturales de Bogotá que estimulado por "los hechos demostrados por la escuela pastoriana" se había dedicado desde 1882 a experimentar un tratamiento parasiticida en una enferma de lepra; se trataba de eliminar los parásitos alojados en su organismo. ${ }^{20}$ Castañeda explicaba que se encontraba realizando esos esfuerzos cuando llegó a sus manos el informe del 2 de febrero de 1884 que el bacteriólogo

\footnotetext{
${ }^{18}$ Sobre Pasteur véase, además de los trabajos citados en la nota 15: Latour B. Les Microbes guèrre et paix suivi de Irreductions. Paris: AM Métailié, 1984 y su versión inglesa, The Pasteurization of France. Cambridge: Harvard University Press, 1988. Sobre Koch véase, Lenoir T. Instituting Science: The Cultural Production of Scientific Disciplines. Stanford, CA: Stanford University Press, 1997 especialmente, el capítulo 7.

${ }^{19}$ Sobre este tema ver: Obregón D. Sociedades científicas en Colombia: la invención de una tradición. Bogotá: Banco de la República, 1992.

${ }^{20}$ Castañeda GJ. Tratamiento parasiticida de la lepra. In:Revista Médica, 1884, 8 (96):513-20.
} 
Robert Koch dirigía al gobierno alemán desde Calcuta, anunciándole el aislamiento ("descubrimiento", en palabras de Castañeda) del microbio del cólera asiático. A Koch (y a su maestro Jacob Henle) se les reconoce, entre otros muchos logros, el haber desarrollado un método experimental para determinar de manera precisa si un microorganismo es la causa específica de una enfermedad. Se trata de los famosos "postulados de Koch" definidos de la manera siguiente: aislamiento (aislar el microorganismo de toda impureza), cultivo (cultivarlo en un medio artificial) e inoculación (inocularlo en un animal de experimentación para producirle una enfermedad semejante a aquélla de la cual se parte). ${ }^{21}$

En el informe a su gobierno, Koch explicaba que no se habían podido encontrar animales que contrajeran el cólera para provocar en ellos artificialmente una enfermedad análoga y así probar que los bacilos encontrados eran la causa de esa dolencia. El informe de Koch, algunos de cuyos apartes son citados por Castañeda, terminaba así:

"El rigor de los hechos enunciados... no podría ser impugnado por el mal éxito de la inoculación sobre los animales. Ocurre lo mismo con otras enfermedades infectivas, tales como el tifus abdominal y la lepra, dos enfermedades producidas igualmente por bacillus específicos que hasta ahora no se han podido reproducir en los animales, aun cuando su manera de ser sea tal, que los bacterios deban considerarse indudablemente como la causa de estas enfermedades". ${ }^{22}$

La lectura del informe de Koch suscitó en Castañeda una reacción de optimismo. Para él, las investigaciones sobre el cólera demostraban que la lepra era curable, a diferencia de lo que se pensaba. Según Castañeda, hasta entonces se trabajaba con el bastón del empirismo, pero ahora, gracias a la luz de la ciencia que había establecido la existencia de un bacilo específico

\footnotetext{
${ }^{21}$ Moulin AM. Le dernier langage de la médecine: Histoire de l'immunologie de Pasteur au Sida. Paris: Presses Universitaires de France, 1991: 30.

${ }^{22}$ Castañeda. Tratamiento parasiticida de la lepra: 519
}

para la lepra, se podía desarrollar un tratamiento parasiticida específico para curarla. Uno de los rasgos más sobresalientes de la llamada edad de oro de la bacteriología fue justamente su radical y, con frecuencia, ciego optimismo. Muchos investigadores se dedicaron a buscar los microbios causantes de toda clase de enfermedades y hubo quienes creyeron haber encontrado el microorganismo específico del cáncer, de la gota y de muchas más. Sobre el tratamiento parasiticida de Castañeda no se supo mucho más. Probablemente fue olvidado junto a tantos otros remedios que en su momento pretendieron curar la enfermedad.

No obstante, para los médicos colombianos resultaba claro que la revolución de "lo infinitamente pequeño" requería de instituciones de enseñanza e investigación para que rindiera sus frutos. En 1888, el médico Proto Gómez, también miembro de la Sociedad de Medicina, se refería a la importancia de instalar y sostener laboratorios modernos para la enseñanza de la histología, la bacteriología y la medicina legal, entre otras ciencias médicas:

"vemos diariamente que se adquieren elementos de guerra, que llevan la desolación y la muerte entre los mismos hombres por la ingrata suposición de que ellos son nuestros mayores enemigos, gastando cuantiosas sumas, sin pensar siquiera en que los verdaderos enemigos de la especie humana son esos innumerables ejércitos de los infinitamente pequeños, que nos vencen hora por hora, por no conocer los medios necesarios para defendernos y combatirlos". ${ }^{23}$

Desde entonces, las metáforas de guerra en la lucha contra los microbios ya no nos abandonarán. Por lo demás, la palabra microbio ya había entrado en el lenguaje médico corriente. Este nombre fue propuesto en 1878 por CharlesEmmanuel Sédillot, director de la escuela del servicio de salud militar de Strasbourg, después de consultas con el lexicógrafo Emile Littré. Microbio designaría en adelante a esos seres que

\footnotetext{
${ }^{23}$ Gómez P. Importancia de los estudios bacteriológicos.
} In: Revista Médica, 1888, 12 (128): 129-33, en p. 132-33. 
si bien eran micro poseían todas las propiedades de los seres vivos. ${ }^{24}$

Quizás algunos de los médicos que asumieron más cabalmente el programa científico de lá bacteriología en Colombia fueron Juan de Dios Carrasquilla y Federico Lleras Acosta. En una larga polémica contra la teoría de la lepra como una enfermedad hereditaria, Carrasquilla señalaba en 1889 , citando a Koch:

"Las enfermedades infecciosas no provienen, como se creía antes de cuerpos fluídos, es decir, gaseosos, de miasmas, sino de cuerpos sólidos, de polvos... Las enfermedades infecciosas no son jamás producidas por el desaseo, por la viciación del aire que proviene de la aglomeración de hombres, por el hambre, la pobreza, las privaciones, ni por la suma de todos estos factores, que es lo que se ha llamado miseria social, ni por las influencias climatéricas. Sus gérmenes específicos son los únicos que pueden producirlos (sic)". ${ }^{25}$

Carrasquilla continuaba explicando que así como una enfermedad no aparece si no existe el microorganismo especial que la produce, una enfermedad tampoco se transforma en otra, ni un microbio engendra otro de distinta especie. Tampoco las enfermedades de los padres se pueden transmitir a los hijos por vía de generación, ellas sólo se transmiten por contagio o por infección. ${ }^{26}$ Estas afirmaciones eran importantes por cuanto desde tiempos medievales se había creído que la lepra era el último estadio de la sífilis y se la había confundido con muchas otras dolencias. Por lo demás, médicos tan importantes en el estudio de la lepra como los noruegos Daniel Danielssen y Carl W. Boeck quienes habían realizado su descripción anatomopatológica en 1847 , la tenían por hereditaria. ${ }^{27}$

\footnotetext{
${ }^{24}$ Raichvarg, Louis Pasteur: 69.

${ }^{25}$ Carrasquilla JD. Disertación sobre la etiología y el contagio de la lepra. In: Revista Médica, 1889, 13 (137):44184 , en p. 465.

${ }^{26}$ lbid.: 468.

${ }^{27}$ Danielssen DC and Boeck CW. Traité de la Spedalsked ou Eléphantiasis des Grecs. Monograph. Paris: J.B. Ballière, 1848 y Atlas de la Lèpre par D.C. Danielssen et C.W. Boeck, Bergen en Norvèege, 1847 Édition commemorative du centenaire. Rio de Janeiro, 1946.
}

La convicción de la certeza del método bacteriológico llevó a Carrasquilla a buscar posibilidades terapéuticas para la lepra. De esta manera nació la seroterapia Carrasquilla. La sero-terapia se basaba en un principio explicado por el alemán Emil von Behring y por el japonés Shibasaburo Kitasato en 1890. Estos científicos inocularon conejos y ratones con cultivos de tétano y encontraron que su inmunidad dependía de la capacidad del suero de neutralizar las toxinas producidas for el bacilo del tétano. Esta capacidad era durable y además podía ser transferida a otros animales. El éxito de las antitoxinas contra el tétano y luego contra la difteria en la época dorada de la bacteriología, hizo pensar que la seroterapia era la panacea contra las enfermedades infecciosas hasta el primer accidente fatal ocurrido en 1896. Como medida preventiva, el médico alemán Langerhans inoculó antitoxinas a su hijo en perfecta salud, causándole la muerte. ${ }^{28}$ Además, los científicos pronto encontraron que en muchos casos no había diferencia entre el suero inmune y el normal; ambos podían eventualmente conferir inmunidad. En consecuencia, el suero no parecía ser un tratamiento específico y la seroterapia fue abandonada. ${ }^{29}$

El patólogo vienés Victor Babes había intentado la seroterapia inoculando enfermos de lepra con suero de perros que habían sido inmunizados contra la tuberculosis; este suero producía un efecto tónico en los pacientes. ${ }^{30}$ Carrasquilla, en cambio, prepaba el suero directamente de la sangre de los pacientes de lepra usando caballos; su método se inspiraba en la analogía entre la lepra y la sífilis. ${ }^{31}$ El gobierno colombiano entonces creó el Instituto Seroterapéutico para

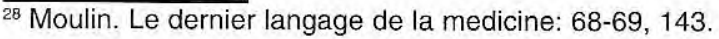

${ }^{29}$ Bulloch W. The History of Bacteriology. New York: Dover, 1938/1979: 261-264.

${ }^{30}$ Rogers L. y Muir E. Leprosy. New York: William Wood, 1925: 250.

${ }^{31}$ García P. Comunicaciones sobre el empleo de la seroterapia en la lepra, hechas a la Academia Nacional de Medicina de Bogotá (Colombia) por el señor doctor Juan de D. Carrasquilla L. In: Revista Médica, 1895, 18 (204):296-308, en pp. 296-8 (nota), 307-8.
} 
proseguir estas investigaciones..$^{32} \mathrm{~A}$ pesar de los deseos de Carrasquilla y de la retórica oficial que lo presentaba a como "el salvador" de los leprosos, los resultados eran diversos: algunos pacientes mejoraban, mientras que en otros los síntomas se agravaban. ${ }^{33}$ Estos experimentos tuvieron amplia difusión: por ejemplo, en la Real Academia de Medicina de Madrid se informó sobre el "método Carrasquilla" en $1896 .{ }^{34}$ En 1897 , Carrasquilla asistió como delegado de Colombia al Congreso Internacional de la Lepra de Berlín donde la seroterapia fue uno de los temas de discusión. ${ }^{35}$ Este congreso puso de presente que el suero Carrasquilla había sido puesto a prueba por los investigadores alemanes Edward Arning y Albert Neisser y por científicos de Argelia, Londres y Copenhage; también había sido usado en el hospital de Saint Louis de París, en la Escuela Hematológica de Viena y en el hospital para leprosos de Robben Island en Sur Africa. Sin embargo, el juicio del congreso de Berlín no fue favorable para Carrasquilla; la Academia Colombiana de Medicina conceptuó que el método era inocuo $y$, aunque lo estimulaba a continuar sus investigaciones, el gobierno le retiró su apoyo. ${ }^{36} \mathrm{El}$ Instituto seroterapéutico decayó y con él murió el sueño de Carrasquilla de convertir este centro de investigación en un Instituto Pasteur en Colombia, al estilo de los que exis-

\footnotetext{
${ }^{32}$ Rico E. Doctor Juan de Dios Carrasquilla. In: Repertorio de Medicina y Cirugía, 1925, 16-7 (187):304-13, en p. 307.

${ }^{33}$ Gutiérrez A. Apuntamientos para la historia de Agua de Dios. Bogotá: Imprenta Nacional, 1925: 33.

${ }^{34}$ Actas de sesiones literarias. In: Anales de la Real Academia de Medicina, 1896, 16:61-69; ver también: San Martín I. La lepra en la España del siglo XIX. Cuadernos Valencianos de Historia de la Medicina y de la Ciencia Valencia, 1966: 85-86.
}

${ }^{35}$ Carrasquilla JD. Memoria sobre la Lepra Griega en Colombia. In: Mittheilungen und Verhandlungen der internationalen wissenschaftlichen Lepra-Conferenz zu Berlin im October 1897 vol. 1. Berlin: Verlag von August Hirschwald, 1897: 81-124.

${ }^{36}$ Conferencia Internacional sobre la lepra, habida en Berlín del 11 al 16 de Octubre de 1897 (Extracto de las discusiones hecho por el Dr. E. Kummer para la Semaine Médicale de París, traducido por el Dr. M.N. Lobo). In: Revista Médica, 1898, 20 (228):269-82). tían en Túnez, Saigón o Marruecos. ${ }^{37}$ Ahora bien, en un momento determinado de este proceso, se presentó una polémica con otro médico colombiano, Carlos Putnam, quien había iniciado la aplicación de la seroterapia en el lazareto de Agua de Dios. ${ }^{38}$ Carrasquilla protestó ante la Academia de Medicina porque consideró que se le estaban usurpando sus derechos de prioridad por el invento del método. Putnam tuvo que suspender sus experimentos con los leprosos y la Academia dictaminó que la prioridad de la invención de la seroterapia correspondía a Carrasquilla. ${ }^{39}$

Este último caso muestra varias diferencias con los ejemplos anteriores. De una parte, pone en evidencia el nuevo papel social y científico de la profesión médica. Putnam tuvo que suspender sus experimentos en Agua de Dios mientras el asunto de la seroterapia se definía en otra instancia: la Academia de Medicina. Hasta entonces, debido a que la práctica médica estaba escasamente regulada, el éxito o el fracaso de los tratamientos empíricos ofrecidos por médicos o por curanderos permanecía como un asunto privado. Con la profesionalización de la medicina, las cuestiones relativas a la terapéutica pasaron a ser del dominio de un cuerpo profesional que poseía el poder de aprobar o de rechazar una determinada práctica. En segundo lugar, el análisis de la historia de la seroterapia Carrasquilla muestra que ya existía en Colombia una profesión para la cual la investigacion científica era importante. Los médicos comenzaban a derivar su prestigio profesional de este tipo de estudios, más que de una relación privada con una clientela.

\footnotetext{
${ }_{37}$ Sobre los Institutos Pasteur en Asia y Africa, véase: Moulin AM. Patriarchal Science: the Network of the Overseas Pasteur Institutes. In: Petitjean P, Jami C \& Moulin AM, editors. Science and Empires: Historical Studies about Scientific Development and European Expansion. Dordrecht: Kluwer Academic Press, 1992: 307-322.

${ }^{38}$ Gutiérrez. Apuntamientos: 31.

${ }^{39}$ Rico E. Doctor Juan de Dios Carrasquilla. In: Repertorio de Medicina y Cirugía, 1925, 16-7 (187):304-13, en p. 307.
} 


\section{De nuevo, el carbón bacteridiano}

En el año de 1906, se presentó una epidemia de carbón bacteridiano en el ganado vacuno en Colombia. El joven veterinario Federico Lleras Acosta fue llamado para atenderla. Lleras se había graduado en la escuela de veterinaria de la Universidad Nacional fundada por el veterinario francés, Claude Vericel. A propósito de esta epidemia, Lleras publicó varios artículos en la $R e$ vista Nacional de Agricultura aclarando que la enfermedad era una fiebre carbunclosa o carbón..$^{40}$ Es decir, se trataba de la misma que había atacado a las vacas de la sabana en 1869 y la misma descrita por Davaine desde 1850. Como los hacendados insistían en confundir el carbón con la llamada ranilla, Lleras se dedicó, en compañía del médico y bacteriólogo Roberto Franco, a investigar el problema. Estas investigaciones permitieron a Lleras escribir una memoria científica por la cual se le nombró miembro de número de la Academia Nacional de Medicina en 1907..11 En este trabajo, Lleras elaboró la distinción entre carbón sintomático y fiebre carbunclosa y describió la bacteria específica que correspondía a cada una de estas enfermedades. De otra parte, la madurez científica de Lleras se hizo evidente en la forma como utilizó la teoría científica y la amplió, adaptándola a las condiciones locales. Los autores europeos afirmaban que el carbón aparecía en los animales de la especie bovina de la edad de seis meses a cuatro años. Lleras afirmaba haber observado la enfermedad en terneros de uno a dos meses y también en animales adultos. Asimismo, Lleras se distanciaba del saber común: los animales predilectos para contraer la enfermedad eran los que parecían estar en mejores condi-

\footnotetext{
${ }_{40}$ Lleras F. El carbón bacteridiano. In: Revista Nacional de Agricultura, 1906, 1 (6): 44-48. Las recientes epizootias. In: Revista Nacional de Agricultura, 1906, 1 (15): 343-4.

41 Lleras F. Contribución al estudio del carbón sintomático. In: Revista Médica, 1907, 27 (324): 258-66. Por lo demás, resulta importante destacar el papel que jugaba la memoria cientifica. Además de posibles patentes, la publicación ya se había convertido en el producto final de la investigación científica. Sobre el papel que juega la escritura como producto final del trabajo científico moderno, véase: Latour B. y Woolgar S. Laboratory Life: The Construction of Scientific Facts. London \& Beverly Hills: Sage, 1979.
}

ciones. Lleras demostró experimentalmente que la tierra donde había ganado enfermo de carbón, estaba también infestada. Por lo tanto, recomendó que se hiciera obligatoria la cremación de los cadáveres carbunclosos y siguiendo la práctica ya rutinaria de los pastorianos, Lleras atenuó la virulencia del bacillus Chauveai y produjo vacunas que resultaron más activas y eficaces que las importadas.

Con la práctica de fabricar vacunas en su laboratorio privado, Lleras hizo efectiva una novedosa manera de comercializar el conocimiento. Ésta es otra de las características destacadas de una ciencia que se practica no solamente por la ideología "del bien de la humanidad" sino también porque es un buen negocio, como será la tecno-ciencia moderna. ${ }^{42}$ Pero Lleras no trabajaba por negocio, aunque la fabricación de vacunas y de sueros era su forma de ganarse la vida. Lleras vivía de y para la ciencia. Por otra parte, Lleras también pronunciaba conferencias públicas y hablaba en lenguaje senciIlo, para que los no-especialistas pudiesen comprender la importancia que tenían los gérmenes tanto para la vida cotidiana como para la economía. Por ejemplo, indicaba a los hacendados que los métodos empíricos y rudimentarios perjudicaban sus negocios: la falta de vacunas y de conocimiento veterinario era fuente de daño para su riqueza. Lleras también se dirigía a las madres de familia para explicarles la importancia de una buena nutrición para los niños y para prevenirlas sobre los microbios que podrían matar a sus hijos. De esta manera, Lleras les aseguraba que su conocimiento bacteriológico podría salvar tanto a los niños como a los negocios y, en consecuencia, evitar la ruina del país entero. Lleras era un pastoriano cabal, convencido del papel que el nuevo saber tenía para el engrandecimiento de la nación.

\section{Cólera, peste bubónica y patriotismo}

El patriotismo fue un rasgo notable de la ciencia de Pasteur y de Koch. En 1883, durante una

\footnotetext{
42 Sobre la noción de "tecno-ciencia" ver: Latour B. Science in Action: How to Follow Scientists and Engineers through Society. Cambridge, MA: Harvard University Press, 1987.
} 
nueva pandemia de cólera, sendas expediciones científicas fueron enviadas a Egipto por parte de Francia y de Alemania, con el fin de aislar el microbio de la enfermedad. ${ }^{43}$ Más que altruismo científico, los dos países se encontraban en una competencia nacionalista en la que pretendían dirimir en el terreno científico parte de sus disputas políticas y militares. La expedición francesa se encontraba a cargo de los discípulos de Pasteur, la primera generación de pastorianos, y la alemana era dirigida por el mismo Robert Koch. La prioridad correspondió a Koch quien desde Calcuta informó de su éxito al aislar el microorganismo, mientras que a la misión francesa correspondió la tragedia y el heroísmo, dos características que estarán ligadas al imaginario de la bacteriología en esta era dorada. Uno de los expedicionarios, el joven discípulo de Pasteur, Louis Thuillier, murió en Alejandría contagiado por el cólera.

En cuanto a Lleras, él fue ante todo un patriota y se vio envuelto en disputas científico-nacionalistas con bacteriólogos norteamericanos de la Fundación Rockefeller. Entre 1913 y 1914 se presentó en Santa Marta - donde operaba la United Fruit Company- una enfermedad infecciosa de elevada mortandad y cuyas características clínicas hicieron pensar a los médicos locales que se trataba de peste. Se declaró el estado de alerta, pero luego se afirmó que no se trataba de esta enfermedad. Un bacteriólogo norteamericano contratado por la compañía bananera diagnosticó neumonía. Sin embargo, algunos médicos locales dudaron de este diagnóstico debido a que la epidemia ya había pasado cuando llegó el bacteriólogo de la United Fruit y su investigación se basó únicamente en preparaciones que le ofrecieron. Al presentarse nuevos casos sospechosos entre los trabajadores bananeros varios meses más tarde, se le pidió a Lleras estudiar dos muestras bacteriológicas. Una discusión sobre el tema se adelantó en la Academia Nacional de Medicina. Después de escuchar el criterio de Lleras y de otros médicos y bacteriólogos, la Academia conceptuó que la epidemia que se había presentado en al-

43 Dubos R. Louis Pasteur: franc-tireur de la science. Paris: Presses Universitaires de France, 1955: 272-3. gunas poblaciones de la costa Atlántica era, en efecto, peste bubónica, a fin de que el gobierno tomara las medidas correspondientes. Por lo demás, Lleras publicó un artículo en el cual describía cuidadosamente el bacilo de la peste, identificado por Shibasaburo Kitasato y Alexandre Yersin en 1894, y los detalles técnicos para su observación y cultivo a fin de realizar un diagnóstico bacteriológico correcto. ${ }^{44} \mathrm{~Pa}$ blo García Medina, una figura destacada en el establecimiento de la política sanitaria del país describía la situación en los siguientes términos:

"...llegó un bacteriólogo americano a los lugares infectados y en treinta horas de permanencia decidió que la enfermedad no era peste sino una neumonía infecciosa... A pesar ... del concepto de médicos de Barranquilla, todo se calmó con la rotunda afirmación del bacteriólogo americano del Norte". En la zona bananera... se siguieron presentando casos entre los trabajadores, que eran calificados de fiebres palúdicas por los médicos americanos". ${ }^{45}$

A propósito de la peste, el médico J. Rafael Ferreira de Bogotá también protestó airado en defensa de la profesión médica nacional:

"No hay que compartir la opinión de los que creen que sólo los bacteriólogos extranjeros son capaces de ponerse a cubierto de las críticas que se puedan hacer a las manipulaciones de laboratorio; hay que convenir en que aquí también hay elementos e individuos para poder hacer eso mismo sin tener que recurrir a otras partes..." 46

Estas polémicas entre médicos colombianos y expertos norteamericanos revelan la existencia de resistencias por parte de la organización médica nacional ante los avances de la Fundación Rockefeller en este período. ${ }^{47}$

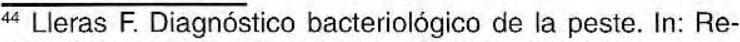
vista Médica de Bogotá, 1914, 32 (383): 236-244.

${ }^{45}$ Actas de la Academia (Sesión del 22 de Mayo de 1914). In: Revista Médica de Bogotá 32, 384 (Jun. 1914): 381-2.

${ }^{46}$ Ferreira JR. El diagnóstico bacteriológico de la peste bubónica. In: Repertorio de Medicina y Cirugía, 1914, 5-8 (56):420-3.
} 
Los casos de Carrasquilla y de Lleras Acosta muestran que ya desde finales del siglo XIX existía en Colombia una medicina experimental en manos de médicos y una práctica bacteriológica, más allá de la retórica acerca de su importancia. En la época de Castañeda no existía aún esa medicina de laboratorio: Castañeda vivió la influencia de la nueva ciencia de los gérmenes con el entusiasmo típico de esta era, pero su tratamiento parasiticida se encontraba distante de los métodos que harían tan famosos a Pasteur y a Koch.

\section{Conclusiones}

El examen de la historia de algunas epidemias y enfermedades en lo que hoy es Colombia muestra la transición de una medicina de corte miasmático a una medicina bacteriológica practicada por profesionales. Antes que colocar el énfasis en las transformaciones de la ideas médicas que se recibían de los centros científicos europeos se ha realizado un análisis de los actores locales que hicieron posibles los cambios tanto en las ideas como en las prácticas de salud pública. La organización de la profesión médica representa un momento importante en tal transición. Equipos de especialistas interesados en acrecentar su conocimiento y su poder reemplazaron a los grupos de notables a quienes previamente se encomendaba el control de las epidemias.

De manera más general se puede concluir que el arraigo de la actividad científica se plasma en la consolidación de instituciones, de laboratorios y de cuerpos profesionales interesados en la ciencia. Más que un asunto de genios indivi-

\footnotetext{
47 Estas resistencias, sin embargo, no han sido suficientemente exploradas en los estudios que tratan este tema. Ver por ejemplo: Quevedo E. JPolíticas de salud o políticas insalubres? De la higiene a la salud pública en Colombia en la primera mitad del siglo $X X$. In: Biomédica 1996; 16 (4):345-359. Por lo demás, el papel de los médicos colombianos en el desarrollo de la salud pública es minimizado en los trabajos de Abel C. External Philanthropy and Domestic Change in Colombian Health Care: The Role of the Rockefeller Foundation, ca. 19201950. In: Hispanic American Historical Review 1995; 75 (3):339-376 y Health Care in Colombia c.1920-c.1950: A Preliminary Analysis. London: University of London, 1944.
}

duales, la ciencia requiere la conformación de redes sociales más allá de los científicos mismos. Estas redes prestan su apoyo y la hacen posible. Esto es, el conocimiento científico, las disciplinas se construyen socialmente. Por el solo poder de su veracidad las ideas científicas no se difunden ni se convierten en saberes dominantes. Son los grupos de científicos organizados quienes construyen los saberes que requieren. No se trata sólo de colocar el acento del análisis en lo local sino también de mostrar como operan socialmente esos actores. Sin una comunidad que estimulara y apoyara la investigación bacteriológica ésta no hubiese sido posible.

De otra parte, el análisis del fracaso en la práctica científica es tan importante como el del éxito. Podría objetarse que el "método Carrasquilla" después de todo no puede considerarse un método científico puesto que no sirvió para curar la lepra y hoy en día sólo existe para los historiadores de la ciencia. Lo mismo podría decirse de algunos de los trabajos que intentó Lleras a los que no me he referido aquí. ${ }^{48} \mathrm{Sin}$ embargo, el tipo de práctica científica que estaban desarrollando los discípulos de Pasteur y de Koch alrededor del mundo era muy semejante a la de Carrasquilla o de Lleras. En el Instituto Pasteur de París, en el Instituto Rockefeller, en el Instituto Oswaldo Cruz del Brasil, en Egipto, o en Marruecos, Ios fracasos y los éxitos se distribuían casi por igual. Por supuesto que a la postre, los institutos de investigación mejor dotados, con importantes apoyos estatales o privados realizarían las contribuciones más relevantes.

Este trabajo fue leido en la sesión del 27 de septiembre de 1997 en la cátedra Manuel Ancízar sobre historia de la medicina de la Universidad Nacional de Colombia.

\footnotetext{
48 Sobre el caso de Lleras Acosta véase: Obregón D. De la veterinaria a la bacteriología: Federico Lleras Acosta o la lucha por la construcción de una carrera científica en Colombia. In: Arboleda LC. y Osorio C, editors. Nacionalismo e internacionalismo en la historia de las ciencias y la tecnología en América Latina (Memorias del IV Congreso Latinoamericano de Historia de las Ciencias y la Tecnología). Cali: Universidad del Valle, 1997: 229-255.
} 